\title{
Stress events and Changes in Dysfunctional Attitudes and Automatic Thoughts Following Recovery from Depression in Inpatient Psychotherapy: Mediation Analyses with Longitudinal Data
}

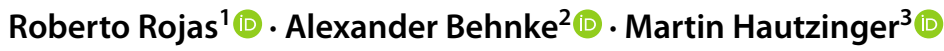

Accepted: 19 November 2021 / Published online: 30 November 2021

(c) The Author(s) 2021

\begin{abstract}
Background Stressful event exposure, dysfunctional attitudes (DA), negative automatic thoughts (NAT), and declining positive automatic thoughts (PAT) have been associated with depressive relapse/recurrence. Few studies have investigated the course of these variables and their relevance for relapse/recurrence in remitted depression.

Methods Following successful inpatient treatment, in 39 remitted depressive patients, stressful events, DA, NAT, PAT, and depressive relapse/recurrence were assessed five times during a 16-month follow-up. Data were analyzed with mixed effect models, and mediation effects were tested.

Results Stressful events after discharge correlated with depressive relapse/recurrence. This association was mainly mediated by a stress-related decline of PAT within four months post discharge. Patients' DA were relatively stable during the observation period and did not depend on stressful events, indicating DA as a risk trait for depressive relapse/recurrence. Mediation analyses revealed that independent of stress, DA were linked to depressive relapse/recurrence through more NAT. Conclusion Our findings suggest stressful events evoke relapse/recurrence in remitted depression through rapid deterioration of PAT after discharge from inpatient therapy. DA are expressed through NAT which additionally contribute to higher risk of depressive relapse/recurrence. Consequently, maintenance therapy requires techniques to promote the maintenance of PAT, and to effectively restructure DA and NAT.
\end{abstract}

Keywords Major depression $\cdot$ Relapse/recurrence $\cdot$ Stress $\cdot$ Dysfunctional attitudes $\cdot$ Automatic thoughts

\section{Introduction}

Currently, about 322 million people worldwide suffer from depressive disorders (WHO, 2017). Depression considerably compromises the physical and mental wellbeing and overall quality of life of affected individuals, and it has relevant negative social and economic consequences (e.g., isolation, unemployment, lower income) (Cambridge et al.,

Roberto Rojas

roberto.rojas@uni-ulm.de

1 University Psychotherapeutic Outpatient Clinic, Institute of Psychology and Education, Ulm University, Schaffnerstraße 3, 89073 Ulm, Germany

2 Clinical \& Biological Psychology, Institute of Psychology and Education, Ulm University, Ulm, Germany

3 Clinical Psychology and Psychotherapy, Eberhard Karls University of Tübingen, Tübingen, Germany
2018; Johnston et al., 2019). Depressive disorders can be effectively treated with psychotherapeutic interventions, with approx. $62 \%$ of patients attaining complete remission (Cuijpers et al., 2014). However, 29\% of them incur depressive relapse/recurrence in the first year and 54\% in the second year after acute-phase cognitive therapy (Vittengl et al., 2007), and a total of up to $80 \%$ of depressed patients experience relapse or recurrence over the course of their lifetime (Wittchen et al., 2010). Thereby, relapse refers to the reappearance of depressive symptoms during remission but before achieving recovery. If the remission is stable for 6-12 months, the depressive episode is usually considered to be over, and thus indicating a recovery. The onset of a new depressive episode after recovery is commonly called recurrence (Bockting et al., 2015). Importantly, the risk for subsequent episodes rises with each additional episode of depression (Beshai et al., 2011; Kendler et al., 2000; Wittchen et al., 2010). For example, relapse/recurrence risk 
after two depressive episodes is $70 \%$ and mounts to $90 \%$ after a third episode (Härter et al., 2017).

Apart from factors like previous depressive episodes and residual symptoms, various studies corroborated exposure to stressful events (e.g., chronic interpersonal stress, acute stressors) as a major risk factor for depressive relapse/recurrence (Bockting et al., 2015). Exposure to stressful events is proposed to be associated with depressive episodes in a dose-response relationship; that is, the more stressful events are experienced, the more depressive symptoms occur (Ayano et al., 2018; Yu et al., 2018).

\section{Beck's Cognitive Model in Depressive Relapse/ Recurrence}

Different theories have been proposed on depression risk and relapse/recurrence. Among them, endogenous risk hypotheses propose the existence of certain risk factors that are present even before the onset of the first depressive episode, whereas scarring hypotheses surmise each depressive episode evokes accumulating "mental damage or scars" which perpetuate the susceptibility to subsequent episodes (Burcusa \& Iacono, 2007). Both perspectives contribute to a better understanding of the onset and maintenance of depression within Beck's cognitive model of depression. Related to the endogenous risk hypothesis, the cognitive model postulates that depression origins from a "cognitive disorder" (Beck, 1967; Beck et al., 1979; Garratt et al., 2007; Thomsen, 2006; Winkeljohn Black \& Pössel, 2015). However, considering the scarring hypotheses, there is increasing evidence that subsequent depressive episodes are associated with an intensification of depressogenic cognitions, which in turn facilitates the risk of a depressive relapse/recurrence (Beck, 2008; Burcusa \& Iacono, 2007).

Beck assumes a person's cognitions are based on attitudes or assumptions (schemas) that are stable cognitive processing patterns formed by experiences in childhood (Otani et al., 2017). In depressed patients, these negative and stereotyped cognitive patterns are called dysfunctional attitudes (DA). In the clinical context, DA are also known as "rules for living" in the form of if-then statements such as "If I am not successful in everything I do, then I must be a failure", or "If I don't meet others expectations, then they will reject me" (Beck, 1979; Conway et al., 2015). Related to DA, depressive patients are prone to cognitive distortions (e.g., selective perception, catastrophizing, arbitrary reasoning) which bias their processing of experiences in an often one-dimensional, global, invariant, absolutizing, or irreversible way. As a result, negative evaluations about the self ("I am useless"), the world ("The world is unfair"), and the future ("It will remain so unbearable") manifest, which Beck calls the cognitive triad. Because of their DA and cognitive distortions, especially in stressful situations, depressive patients' thoughts are often extreme, negative, categorical, absolute, and judgmental. These automatic thoughts are fast-acting, flashing, subjectively plausible and involuntary occurring cognitions which connect an experience (external or internal) with an emotional sensation (consequences). Automatic thoughts can be both positive and negative (Huffziger et al., 2008; Pössel \& Knopf, 2008; Winkeljohn Black \& Pössel, 2015).

Commonly, a "sequential relationship" is assumed between DA and automatic thoughts (Alloy et al., 1985). Thereby, DA are viewed as distal trait-like variable, which are indirectly related to depressive symptoms. Distal variables function at a deep level and exert their depressive influence mainly through facilitating proximal variables such as negative automatic thoughts (NAT; e.g., "Nobody understands me", "What is wrong with me?") which are highly concomitant with depressive symptoms (Kwon \& Oei, 1994; Marchetti et al., 2021; Oei \& Sullivan, 1999). Corroborating this, a meta-analysis assembling 140 cross-sectional studies confirmed that individuals reporting more NAT and DA also show more depressive symptoms; however, compared to DA, NAT is more closely correlated to depression (Tang et al., 2020).

\section{Dysfunctional Attitudes and Automatic Thoughts in Depressive Relapse/Recurrence}

Nevertheless, there is ample evidence that DA are associated with the occurrence and intensification of depressive symptoms (Faissner et al., 2018; Smith et al., 2018). Indeed, depressed individuals show significantly more DA than subclinical (Miloseva et al., 2018) and healthy groups (Yesilyaprak et al., 2019). In a randomized controlled trial with 264 remitted depressive patients, presence of more DA at the beginning of the study prospectively predicted depressive relapse/recurrence (Brouwer et al., 2019). It is also known that negative or sad mood can lead to increased access to DA. This phenomenon, called cognitive reactivity (Jeanne et al., 1998), presents a risk factor for disorder relapse/recurrence among remitted depressive patients (Otto et al., 2007; Rojas et al., 2014; Scher et al., 2005; Segal et al., 1999, 2006).

Regarding NAT, there is consistent evidence that clinically depressed individuals report more NAT than nondepressed controls (Chahar Mahali et al., 2020; Dobson \& Shaw, 1986; Dozois et al., 2009; Ertekin et al., 2018; Hjemdal et al., 2013; Mohammadkhani et al., 2020; Yesilyaprak et al., 2019), and increase in NAT is viewed as highly relevant for the relapse/recurrence of depression (Pössel \& Knopf, 2008; Riley et al., 2017; Winkeljohn Black \& Pössel, 2015). NAT are conceptualized as a state variable triggered by situational cues (Hollon \& Kendall, 1980; Hollon et al., 1996; Wenzel, 2012). More specifically, stressful 
events were found to trigger a reactivation of DA which can lead to an increase in spontaneously occurring NAT, subsequently promoting the incidence or relapse/recurrence of depression (Lewinsohn et al., 1999, 2001). Indeed, there is evidence that upon stress, increasing NAT are highly predictive for emerging depressive symptoms (Jacobs et al., 2008; Lakdawalla et al., 2007; Tang et al., 2020). However, other studies found no evidence that DA and related NAT mediate the negative effects of stressful events on depression (Lethbridge \& Allen, 2008; Marchetti et al., 2021; Wojnarowski et al., 2019). It was also established that improving depression through psychotherapy accompanies reduction of NAT (Furlong \& Oei, 2002; Riley et al., 2017; Tang et al., 2020).

At the same time, improving depression involves an increase of positive automatic thoughts (PAT), for example, "I can achieve everything " or "I feel good " (Dozois, 2007; Dozois et al., 2009; Shiraishi, 2005). Accordingly, an inverse relationship between PAT and depressive symptoms is assumed (Ingram et al., 1995; Missel \& Sommer, 1983). Indeed, longitudinal studies observed that less occurrence of PAT characterized remitted patients who incurred early relapses after successful psychotherapy (Rojas et al., 2016). In addition, remitted depressive patients experienced less PAT than healthy subjects after negative mood induction, suggesting that PAT may be easily disrupted in remitted depression (Rojas et al., 2016). Accordingly, we expect that less PAT or their decreased occurrence could be a major risk factor for depressive relapse/recurrence. However, as of now, it is unclear if the production of PAT is hindered in individuals with more DA. Moreover, it has not been investigated whether the negative impact of stressful events on depressive relapse/recurrence is mediated through a stress-related decline in PAT occurrence.

\section{Present Study}

To conclude, there is first evidence that stressful events can elicit depressive relapse/recurrence in remitted depressed patients through reactivating DA and subsequently, increasing the occurrence of NAT (Beck \& Haigh, 2014; Scher et al., 2005). At the same time, it needs to be investigated to what extent stressful event exposure and DA jeopardize the stability of remission through lowering the occurrence of PAT. Therefore, in this study, we aim to investigate the sequential mediatory role of DA and automatic thoughts in the relationship between stressful events and depressive relapse/recurrence in remitted depressive patients. Thereby, we hypothesized that, (1) stressful event exposure and (2) more DA increase the risk for depression relapse/recurrence after discharge from acute-phase treatment. Additionally, we hypothesized that the negative effect of stress on remission stability is mediated through (3) stress-related reactivation of DA, and (4) stress-related increase in NAT as well as decrease in PAT occurrence. We also tested whether (5) the negative effect of DA on remission stability is mediated through more NAT and less PAT occurrence.

\section{Methods}

\section{Procedure and Participants}

This study uses longitudinal data from a pre-post-therapy study with a 16-months follow-up phase, which comprised four additional measurement time points. All study procedures were approved by the ethics committee of the Medical School of the University of Tübingen (Germany). Data were collected at the Schön Clinic Roseneck (Germany).

\section{Admission and Psychotherapy}

At admission, the German Structured Clinical Interview for DSM IV-TR (SCID-IV-TR; Wittchen et al., 1997) was conducted to investigate the patients' mental health status. Possible cognitive deficits were evaluated via examining the patients' processing speed and concentration using the Number-Connection Test (Vernon, 1993). Only patients with a current major depressive episode (index episode) were invited to participate in this study. The patients underwent a multimodal inpatient treatment for depressive disorders. The intervention included the routine treatment in psychosomatic clinics in Germany, presenting individual and group cognitive-behavioral psychotherapies with individual-specific add-ons such as relaxation procedures, family counseling, art and body therapy, and support from social workers. If necessary, patients received additional psychopharmacological treatment and medical care. Staff consisted of senior psychologists with a post-graduate training in psychotherapy, experienced physicians specialized on psychosomatic medicine (comprehensive training in psychotherapy), and psychotherapists in training under supervision of aforementioned experts, as well as creative therapists and nurses.

\section{Study Eligibility}

At the beginning of their inpatient treatment, 114 depressed patients were invited to an information event for receiving orientation to the study's objectives and procedures. Out of the patients invited, 62 of them were interested in participation and declared their written informed consent. Among them, 14 patients were not eligible for participation, as they met at least one exclusion criterion: (i) severe neurological or mental comorbidities (e.g., psychotic disorders, bipolar disorder, posttraumatic stress disorder, obsessive-compulsive disorder, addiction disorders, eating disorders, and borderline personality disorder), (ii) treatment 
with electroconvulsive therapy, and (iii) insufficient German language skills.

Furthermore, another nine patients were not included in the follow-up observation study since they did not attain complete remission of depressive symptoms at least four weeks prior to discharge. Complete remission was assumed, if patients scored less than eight points on the German Beck's Depression Inventory, version II (BDI-II; Hautzinger et al., 2006) as self-assessment and less than five points on the Quick Inventory of Depression Symptomatology-Clinician rating 16 Items (QIDS-C-16; Rush et al., 2003). This diagnosis was confirmed using the SCID-IV-TR. Note that in Germany, health insurances approve patients a certain and sufficient time for inpatient treatment. If patients achieve a remission of depressive symptoms before the authorized deadline of inpatient therapy, the remaining time is used to consolidate the learned strategies and impart relapseprevention strategies.

\section{Final Study Cohort}

Finally, 39 patients [age: $25-58, M d n(I Q R)=48(14)$ years], including 21 women, participated in this study. At the therapy admission, 31 of them (79.5\%) exhibited a depressive episode of moderate symptom severity and eight of them (20.5\%) an episode of high symptom severity. Prior to the index episode leading to the inpatient treatment described in this study, the patients reported, on average, a history of two previous depressive episodes and 48 months of recurrent depression (see Table 1). Patients received inpatient treatment for four to 16 weeks (Table 1). At the time of discharge, 27 patients (67\%) took antidepressants (Table 2).

Patients not participating in this study were more depressed and reported more NAT at therapy admission. However, there were no differences with regard to age, sex, and therapy duration as well as DA and PAT at admission (see Table 1). Patients who achieved remission during therapy $(n=39)$ showed a reduction in depressive symptomatology by $M d n(I Q R)=64.2(21.0) \%$ over the course of therapy. In the nine patients ( $n=3$ mild, $n=4$ moderate, $n=2$ severe symptoms) who did not achieve remission, symptom severity was reduced by $M d n(I Q R)=27.9(20.0) \%$ only.

\section{Post-Discharge Assessments}

Within a 16-months follow-up period following discharge, remitted depressed patients were contacted via email to report stressful events, DA, NAT, PAT, and their depressive symptoms (BDI-II, QIDS-C-16). Table 2 shows descriptive statistics about the assessed variables across the measurement time points. In order to minimize possible memory distortions or double counting of stressful events, the follow-up evaluations were carried out every four months. Post-discharge patient contact and their recurrent mental health assessment was carried out by the study coordinator (RR) who is a senior psychotherapist and supervisor

Table 1 Characteristics of remitted depressive patients and excluded patients at therapy admission

\begin{tabular}{|c|c|c|c|}
\hline \multirow[t]{2}{*}{ Characteristics } & Study cohort $(N=39)$ & $\begin{array}{l}\text { Excluded patients and } \\
\text { nonresponders }(N=75)^{\mathrm{a}}\end{array}$ & \multirow[t]{2}{*}{ Group comparison } \\
\hline & $M d n(I Q R)[$ range] $/ n(\%)$ & $M d n(I Q R)[$ range] $/ n(\%)$ & \\
\hline \multicolumn{4}{|l|}{ Demographic data } \\
\hline Age [years] & $48.0(14.0)[25,58]$ & $51.0(21.0)[18,66]$ & $U=1352.5, z=-0.66, p=0.511$ \\
\hline Female sex & $21(53.8 \%)$ & $43(57.3 \%)$ & $p_{\text {Fisher }}=0.843$ \\
\hline Living in partnership & $24(61.5 \%)$ & - & \\
\hline Regular employment/of them in part-time & $33(84.6 \%) / 6(15.4 \%)$ & - & \\
\hline \multicolumn{4}{|l|}{ Depression characteristics } \\
\hline Number of depressive episodes & $2(2)[1,8]$ & - & \\
\hline Duration [months] & $48(155)[3,720]$ & - & \\
\hline Severity at admission, moderate / severe & $31(79.5 \%) / 8(20.5 \%)$ & - & \\
\hline Self-rated depressive symptoms (BDI-II) & $21(13)[13,38]$ & $30(19)[15,47]$ & $U=739.5, z=-4.32, p<0.001$ \\
\hline Clinician-rated depressive symptoms (QIDS-C-16) & $12(5)[8,20]$ & - & \\
\hline Duration of inpatient clinic stay [weeks] & $7(4)[4,16]$ & $8(3)[5,12]$ & $U=1276.0, z=-1.13, p=0.258$ \\
\hline \multicolumn{4}{|l|}{ Cognitive variables } \\
\hline Dysfunctional attitudes (DAS-18-A) & $71(32)[40,98]$ & $74(30)[41,117]$ & $U=1137.5, z=-1.75, p=0.081$ \\
\hline Negative automatic thoughts (ATQ-11-A) & $1.7(1.0)[1.0,3.5]$ & $2.5(1.5)[1.2,4.5]$ & $U=721.0, z=-4.30, p<0.001$ \\
\hline Positive automatic thoughts (ATQ-11-A) & $3.6(1.4)[1.8,5.0]$ & $4.0(1.2)[1.8,5.0]$ & $U=1130.5, z=-1.59, p=0.112$ \\
\hline
\end{tabular}

${ }^{\mathrm{a}}$ Excluded patients: $N=66$, Nonresponders: $N=9$ 
Table 2 Descriptive statistic of study variables by measurement time point

\begin{tabular}{|c|c|c|c|c|c|}
\hline & \multicolumn{5}{|c|}{ Descriptive statistics $M d n(I Q R) / n(\%)$} \\
\hline & Discharge & 4 months follow-up & 8 months follow-up & 12 months follow-up & 16 months follow-up \\
\hline $\begin{array}{l}\text { Self-reported depressive symptoms } \\
\text { (BDI-II) }\end{array}$ & $7.0(3.0)$ & $10.0(14.0)$ & $11.0(17.0)$ & $13.0(17.0)$ & $13.0(15.0)$ \\
\hline $\begin{array}{l}\text { Clinician-rated depressive symptoms } \\
\text { (QIDS-C) }\end{array}$ & $5.0(3.0)$ & $6.0(9.0)$ & $5.0(10.0)$ & $6.0(9.0)$ & $6.0(10.0)$ \\
\hline Patients with depressive relapse & $0(0.0 \%)$ & $12(30.8 \%)$ & $14(35.9 \%)$ & $17(43.6 \%)$ & $18(46.2 \%)$ \\
\hline Dysfunctional attitudes (DAS-18-A/B) & $60.0(25.0)$ & $65.0(27.0)$ & $64.0(35.0)$ & $65.7(25.0)$ & $67.7(23.0)$ \\
\hline $\begin{array}{l}\text { Negative automatic thoughts } \\
\text { (ATQ-11-A/B) }\end{array}$ & $1.83(1.17)$ & $1.83(1.00)$ & $2.17(1.50)$ & $2.17(1.33)$ & $2.17(1.17)$ \\
\hline $\begin{array}{l}\text { Positive automatic thoughts } \\
\text { (ATQ-11-A/B) }\end{array}$ & $6.67(3.17)$ & $2.67(1.50)$ & $2.42(1.33)$ & $2.29(1.50)$ & $2.45(1.42)$ \\
\hline $\begin{array}{l}\text { Stressful event exposure (QLE), } \\
\text { cumulated across follow-up }\end{array}$ & - & $3.0(3.0)$ & $6.0(4.0)$ & $8.0(6.0)$ & $11.0(8.0)$ \\
\hline Antidepressant medication & $27(69.2 \%)$ & $24(61.5 \%)$ & $20(51.3 \%)$ & $19(48.7 \%)$ & $19(48.7 \%)$ \\
\hline Outpatient psychotherapy & - & $29(74.4 \%)$ & $26(66.7 \%)$ & $22(56.4 \%)$ & $21(53.8 \%)$ \\
\hline
\end{tabular}

with official German state recognition. If the BDI-II score exceeded 14 points (i.e., mild depressive symptoms), RR contacted patients via telephone within one week to determine possible relapse/recurrence of depression using the QIDS-C-16. If the QIDS-C-16 score exceeded seven points (Trivedi et al., 2004), the SCID-IV-TR depression module was used to confirm the diagnosis of depressive relapse/ recurrence. In this case, patients received a telephonebased counseling. Note that we use the term "relapse/ recurrence", as our follow-up observation period covers 16 months. Therefore, reappearance of depressive symptoms can be both relapse and recurrence depending on the actual time point.

\section{Clinical Questionnaires}

The patients' age, sex, family status, educational level, employment status, and physical health condition were assessed at study enrollment.

\section{Depressive Symptoms}

Severity of depressive symptoms was determined using the BDI-II as self-assessment and the QIDS-C-16 as clinician rating. The BDI-II (Hautzinger et al., 2006) enables to assess the severity of depressive symptoms on 21 items, and showed a high internal consistency $\alpha=0.89$, a good test-retest reliability $r_{t t}=0.78$, and good content validity. In this study, the BDI-II had a high internal consistency of $\alpha=$ 0.83. The QIDS-C-16 (Rush et al., 2003) allows a clinician to record the severity of patients' depressive symptoms on 16 items. The inventory has a good internal consistency of $\alpha=0.86$ as well as a very good content, convergent, discriminant, and construct validity.

\section{Dysfunctional Attitudes}

In order to minimize possible effects of repeated testing within a short period of time, two short versions of the following questionnaires were used: instead of the 40-item German Dysfunctional Attitude Scale (DAS; Hautzinger et al., 2005), two parallel forms with 18 items each (DAS-18 Form A and B; Rojas et al., 2015) were employed. In a validation study (Rojas et al., 2015), the parallel forms resembled the DAS long version's item assignment to its two subscales 'perfectionistic performance assessment' and 'need for recognition by others'. In our study, the DAS parallel versions exhibited a high internal consistency (DAS-18-A $\alpha=0.90$ and DAS-18-B $\alpha=0.89$ ).

\section{Automatic Thoughts}

The German Automatic Thoughts Questionnaire (ATQ) was divided into two parallel scales with 11 items each (ATQ-11 Form A and B) according to the item correlations reported in Pössel et al. (2005). Item 17 (“That's great") was assigned to both scales, so that each ATQ short version contained the same number of items (11) with a similar pattern of factor loads. Comparability of the parallel ATQ short scales was confirmed in a study with 94 depressive patients and 110 healthy controls (Rojas et al., 2016). In this study, the ATQ parallel versions showed a high internal consistency (ATQ11-A: $\alpha=0.88$; ATQ-11-B: $\alpha=0.83$ ).

\section{Stressful Events}

To identify exposure to stressful events during the follow-up period the Questionnaire for Recording Life Events (QLE; Lewinsohn et al., 2003) was used to record exposure to 31 
life events which preceded each measurement time point within the previous four months. Patients were asked to also indicate the perceived valence of each experienced event (i.e., positive or negative) and to rate its stress intensity on a 4-point Likert scale $(1=$ not at all, $2=$ a little, $3=$ somewhat, $4=$ very strongly). In a previous study among German participants, the instrument showed good psychometric properties (Rojas et al., 2014). For subsequent analyses we used the number of all stressful events (both positively and negatively connoted) the patients had experienced between the measurement time points.

\section{Statistical Analysis}

Spearman rank correlations for repeated measures were computed (using the R package rmcorr; Bakdash \& Marusich, 2016) since majority of variables were non-normally distributed. Friedman tests were conducted to examine whether depressive symptoms and cognitive variables changed across the follow-up. Durbin-Conover tests served as post-hoc tests applying a Holm correlation to adjust $p$ values for multiple testing.

Associations of depressive relapse/recurrence (as binary outcome variable), DA, and automatic thoughts were analyzed with linear and logistic mixed effect models with restricted maximum likelihood (REML) estimators (using the R packages lme4; Bates et al., 2015; and lmerTest; Kuznetsova et al., 2016). Random intercepts $\left(U_{0 \mathrm{j}}\right)$ were modelled to map the repeated measurement character of the data (i.e., the five time points, $\mathrm{t}_{1}$ : therapy discharge, $\mathrm{t}_{2}: 4$ months follow-up, $\mathrm{t}_{3}: 8$ months follow-up, $\mathrm{t}_{4}: 12$ months follow-up, $t_{5}: 16$ months follow-up).

We used a stepwise modelling procedure to test for mediation effects (Baron \& Kenny, 1986): (1), depressive relapse/recurrence was statistically predicted by the participants' cumulated exposure to stressful events at each time point (model: Relapse/recurrence $\sim$ stressful events $+U_{0 j}$ ). (2), DA were included as mediator between stressful events and depressive relapse/recurrence (model: Relapse/recurrence $\sim$ stressful events $+\mathrm{DA}+U_{0 \mathrm{j}}$ ). (3), PAT and NAT were entered as mediators between stressful events and DA as well as depressive relapse/recurrence (model: Relapse/recurrence $\sim$ stressful events $+\mathrm{DA}+\mathrm{PAT}+\mathrm{NAT}+U_{0 \mathrm{j}}$ ). Moreover, (4), DA were predicted by stressful events, and (5), PAT and NAT were predicted by stressful events and DA. We statistically controlled the patients' history of major depression episodes prior to the index episode leading to the inpatient treatment described above.

All analyses were repeated with linear mixed effect models to predict the course of depressive symptoms (i.e., the BDI-II sum score) as outcome variable.

All variables were $z$-standardized for enabling comparability of effects across models. Appropriateness of including additional variables into the models was determined by a relevant reduction of Akaike's information criterion (AIC). Statistical significance of indirect (mediation) effects was determined by $95 \%$ quasi-Bayesian confidence intervals obtained from 5000-times nonparametric bootstrapping (using the $\mathrm{R}$ package mediation; Tingley et al., 2014). A sample size of at least $N=19-24$ is recommended to test longitudinal mediation effects in data with five measurement points, medium- to large-sized mediation paths, and medium ICCs (0.4-0.6) (Pan et al., 2018).

\section{Results}

\section{Preliminary Analyses}

Self-reported depressive symptoms changed significantly within the 16 months post treatment [Friedman- $\left.\chi^{2}(4)=56.27, p<0.001\right]$. Post-hoc tests (Supplementary Table 1) revealed, depressive symptoms increased substantially within the first four months after discharge and subsequently remained on the stable level (Fig. 1a). Linear mixed effect models indicated the course of depressive symptoms after discharge was not associated with the patients' sex, antidepressant medication after discharge, and attendance of outpatient psychotherapy (Supplementary Table 2). However, patients with a history of major depression episodes prior to the index episode leading to the inpatient treatment described above showed quicker depression relapse/recurrence after discharge (Supplementary Table 2). Therefore, we subsequently considered lifetime depression as a covariate when modelling depressive relapse/recurrence and depressive symptoms, respectively.

Moreover, seen on average across all patients, their DA [Friedman- $\chi^{2}(4)=3.81, p=0.433$, Fig. 1b] and NAT [Friedman- $\chi^{2}(4)=5.98, p=0.201$, Fig. 1c] did not alter throughout the observation period. However, the patients indicated their PAT significantly decreased within the first four months after discharge and subsequently remained stable on a comparably low level [Friedman- $\chi^{2}(4)=80.67$, $p<0.001$; Fig. 1d; see Supplementary Table 1 for post-hoc tests].

\section{Exposure to Stressful Events}

Correlations of repeatedly assessed variables are reported in Table 3. Negatively and positively connoted stressful events were both associated with more self-reported and clinician-rated depressive symptoms as well as less PAT in the follow-up. To test our hypotheses, as a first step, we modelled the relevance of stressful events and lifetime depression for depressive relapse/recurrence since discharge (Table 4, Model A). Stressful events $(b=1.56$, OR 4.8, $p<0.001)$ and 

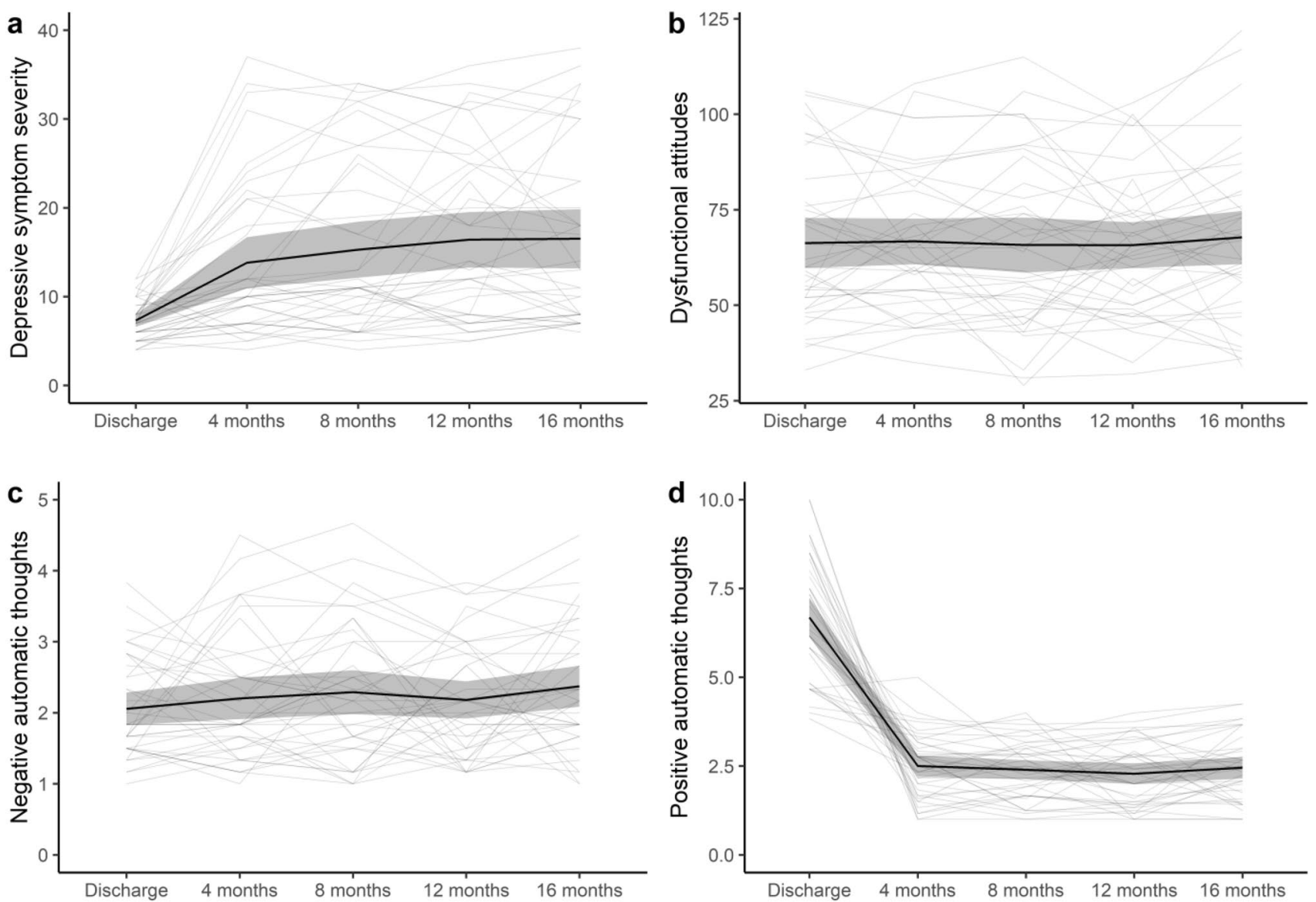

Fig. 1 Individual and averaged (M, 95\% confidence interval) trajectories of (a) depressive symptoms (as assessed with Beck's depression inventory), $\mathbf{b}$ dysfunctional attitudes, $\mathbf{c}$ negative automatic thoughts, and $\mathbf{d}$ positive automatic thoughts

Table 3 Repeated measurement correlations

\begin{tabular}{llllll}
\hline & BDI-II & QIDS-C & DA & NAT & PAT \\
\hline Stressful events (QLE), cumulated & $0.51^{* * * *}$ & $0.51^{* * * *}$ & 0.07 & 0.14 & $-0.57^{* * *}$ \\
Negative stressful events (QLE), cumulated & $0.52^{* * * *}$ & $0.51^{* * *}$ & 0.11 & 0.16 & $-0.56^{* * *}$ \\
Positive stressful events (QLE), cumulated & $0.29^{* * * *}$ & $0.27^{* * *}$ & -0.09 & 0.04 & $-0.40^{* * *}$ \\
Self-reported depressive symptoms (BDI-II) & - & $0.90^{* * *}$ & $0.22^{* * *}$ & $0.55^{* * *}$ & $-0.67^{* * *}$ \\
Clinician-rated depressive symptoms (QIDS-C) & & - & $0.30^{* * *}$ & $0.51^{* * *}$ & $-0.62^{* * *}$ \\
Dysfunctional attitudes (DA; DAS-18-A/B) & & & - & $0.34^{* * *}$ & -0.10 \\
Negative automatic thoughts (NAT; ATQ-11-A/B) & & & & - & $-0.23^{* *}$ \\
Positive automatic thoughts (PAT; ATQ-11-A/B) & & & & & - \\
Intraclass correlation, $r_{\text {ICC }}$ & 0.51 & 0.53 & 0.68 & 0.44 & 0.00 \\
\hline
\end{tabular}

The intraclass correlation estimates the stability of the variables across measurement time points. Levels of two-tailed significance are denoted with ${ }^{*} p<0.050,{ }^{* *} p<0.010,{ }^{* * *} p<0.001$ lifetime depression $(b=3.71$, OR 41.1, $p=0.043)$ increased the risk for depressive relapse/recurrence after discharge.

\section{Dysfunctional Attitudes (DA) as a Mediator}

In the second step, DA were added as a possible mediator between stressful events and depressive relapse/recurrence
(Table 4, Model B). Adding DA improved the explained variance $\left(\mathrm{R}^{2}{ }_{\text {marg }}\right)$ of depressive relapse/recurrence from $33.6 \%$ to $54.8 \%$. More DA implicated higher risk for depressive relapse/recurrence $(b=2.18$, OR $8.8, p<0.001)$. DA were relatively stable within individuals across the follow-up period $\left(r_{\text {ICC }}=0.68\right.$; Table 4; Fig. $\left.1 \mathrm{~b}\right)$ and did not depend on stressful event exposure $(\beta=0.06, p=0.205$; Table 4 , Model 


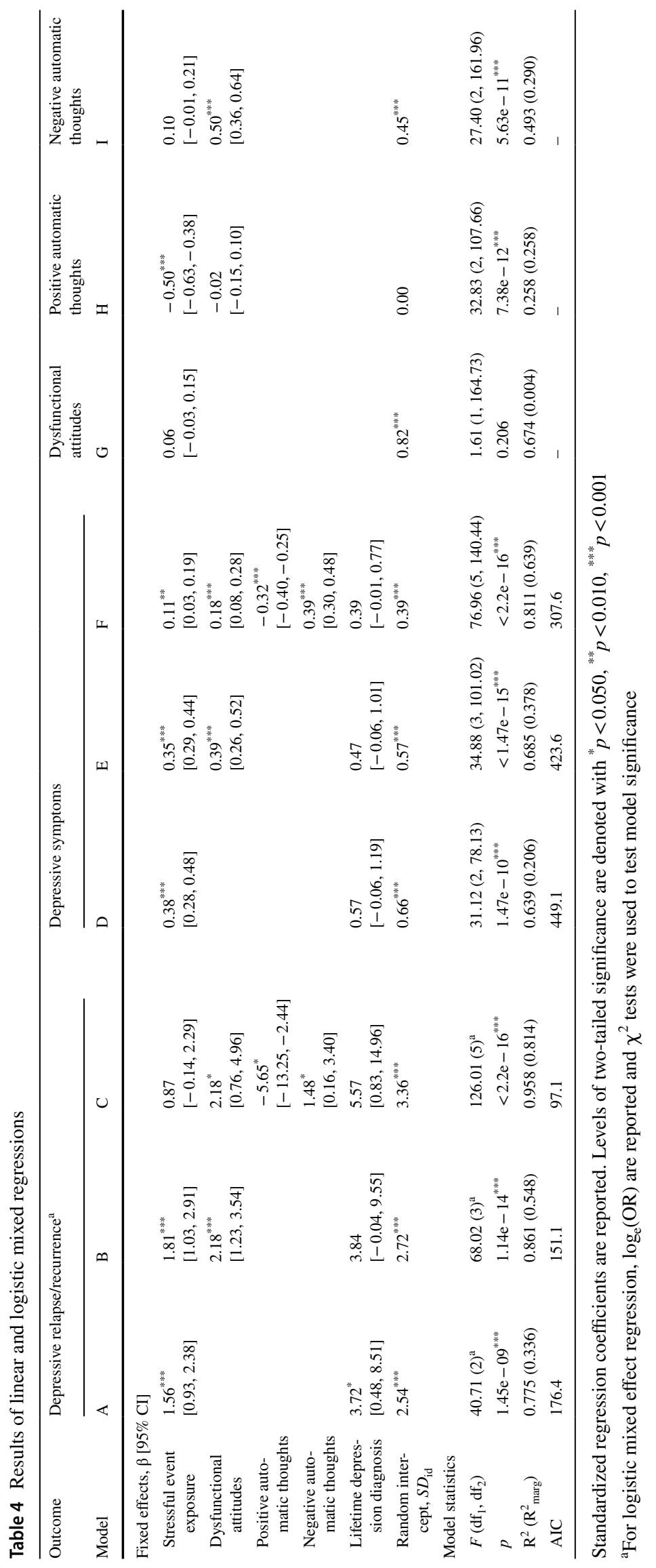


Table 5 Results of mediation analyses

\begin{tabular}{|c|c|c|c|}
\hline & $\beta_{\text {indirect }}$ & $95 \% \mathrm{CI}(\beta)$ & $p$ \\
\hline Stressful events $\rightarrow$ DA $\rightarrow$ PAT & -0.001 & $-0.013,0.010$ & 0.790 \\
\hline Stressful events $\rightarrow$ DA $\rightarrow$ NAT & 0.024 & $-0.021,0.070$ & 0.298 \\
\hline Stressful events $\rightarrow \mathrm{DA} \rightarrow$ relapse/recurrence $^{\mathrm{a}}$ & 0.011 & $-0.006,0.030$ & 0.210 \\
\hline Stressful events $(\rightarrow$ DA $) \rightarrow$ PAT $\rightarrow$ relapse/recurrence ${ }^{a}$ & 0.136 & $0.038,0.220$ & $0.017^{*}$ \\
\hline Stressful events $(\rightarrow \mathrm{DA}) \rightarrow \mathrm{NAT} \rightarrow$ relapse/recurrence $^{\mathrm{a}}$ & 0.010 & $-0.0003,0.030$ & 0.063 \\
\hline $\mathrm{DA} \rightarrow \mathrm{PAT} \rightarrow$ relapse/recurrence $^{\mathrm{a}}$ & 0.006 & $-0.025,0.040$ & 0.719 \\
\hline $\mathrm{DA} \rightarrow \mathrm{NAT} \rightarrow$ relapse/recurrence ${ }^{\mathrm{a}}$ & 0.040 & $0.0002,0.090$ & $0.049^{*}$ \\
\hline Stressful events $\rightarrow$ DA $\rightarrow$ depressive symptoms & 0.023 & $-0.013,0.060$ & 0.210 \\
\hline Stressful events $(\rightarrow$ DA $) \rightarrow$ PAT $\rightarrow$ depressive symptoms & 0.214 & $0.155,0.280$ & $<0.001^{* * *}$ \\
\hline Stressful events $(\rightarrow$ DA $) \rightarrow$ NAT $\rightarrow$ depressive symptoms & 0.076 & $0.029,0.130$ & $0.0012^{* *}$ \\
\hline $\mathrm{DA} \rightarrow \mathrm{PAT} \rightarrow$ depressive symptoms & 0.007 & $-0.033,0.050$ & 0.715 \\
\hline $\mathrm{DA} \rightarrow \mathrm{NAT} \rightarrow$ depressive symptoms & 0.196 & $0.129,0.270$ & $<0.001^{* * *}$ \\
\hline
\end{tabular}

$D A$ dysfunctional attitudes, NAT negative automatic thoughts, PAT positive automatic thoughts

Levels of two-tailed significance are denoted with ${ }^{*} p<0.050,{ }^{* *} p<0.010,{ }^{* * *} p<0.001$

${ }^{a}$ In case of predicting depressive relapse/recurrence with logistic regressions, $b$ values are given which present differences of probabilities/odds

G). Thus, DA did not mediate the association between stressful events and depressive relapse/recurrence $\left(b_{\text {indirect }}=0.001\right.$, $p=0.210$; Table 5).

\section{Negative and Positive Automatic Thoughts as Mediators}

The courses of PAT and NAT were modelled as functions of stressful events and DA (see Table 4, Models H \& I). PAT (Fig. 1d) decreased with exposure to stressful events ( $\beta=-0.50, p<0.001)$ but did not depend on the patients' DA ( $\beta=-0.02, p=0.713)$. Accordingly, the association between stressful events and declining PAT was not mediated through changes in DA ( $\beta_{\text {indirect }}=-0.001, p=0.790$; Table 5). Furthermore, Fig. 1c shows that NAT were relatively stable during the observation period $\left(r_{\mathrm{ICC}}=0.44\right)$, although with higher individual variability than DA (see Table 3). Fluctuation in NAT was not related to stressful events ( $\beta=0.10, p=0.082$ ); however, patients with more DA also reported more NAT $(\beta=0.50, p<0.001)$.

Considering PAT and NAT as predictor variables alongside stressful events, DA, and lifetime depression explained additional $26.6 \%$ of variance $\left(\mathrm{R}^{2}\right.$ marg $)$ in depressive relapse/ recurrence risk (Table 4, Model C; Fig. 2a). DA ( $b=2.18$, OR $8.9, p=0.021)$, PAT $(b=-5.65$, OR 0.004, $p=0.021)$, and NAT $(b=1.48$, OR $4.4, p=0.047)$ were significantly associated with the risk of depressive relapse/recurrence; however, stressful events showed no direct association with the depressive relapse/recurrence risk ( $b=0.87$, OR 2.4, $p=0.126$; Fig. 2a). Lifetime depression was not a significant predictor of depressive relapse/recurrence $(p=0.067)$.

Figure 2a provides a graphical summary of the consecutive models. Mediation analyses showed the association between stressful events and depressive relapse/recurrence risk was mainly mediated through the stress-associated decline in PAT $\left(77.5 \%, b_{\text {indirect }}=0.136, p=0.017\right.$; Table 5). Furthermore, NAT partially mediated the association between patients' DA and depressive relapse/recurrence $\left(b_{\text {indirect }}=0.040, p=0.049\right.$; Table 5).

Note that all analyses were repeated using depressive symptoms (as measured with the BDI-II) as outcome variable which lead to almost identical results. Detailed information of these results can be found in Table 4, Models D-F for linear mixed effect models, and Table 5 for mediation effects. Figure $2 b$ provides a graphical summary of these results.

\section{Discussion}

This longitudinal study examined remitted depressed patients across 16 months after discharge from acutephase inpatient treatment to examine whether higher risk of depressive relapse/recurrence after stressful event exposure is mediated through stress-related changes in DA and automatic thoughts. Consistent with previous studies, higher risk of depressive relapse/recurrence was associated with a history of previous MDD episodes (Burcusa \& Iacono, 2007; Wojnarowski et al., 2019). Besides, our data corroborated that exposure to stressful events in the followup phase was associated with higher risk of depressive relapse/recurrence (Burcusa \& Iacono, 2007; Chen et al., 2017; Hetolang \& Amone-P'Olak, 2018) and an increase in depressive symptoms (Ayano et al., 2018; Gao et al., 2019; Yu et al., 2018). Importantly, we observed that exposure to negatively connoted stressful events as well as experiencing positively connoted stressful events was associated with an increase in depressive symptoms after discharge from 
Fig. 2 Graphical summary of final (a) linear and logistic mixed effect models to predict depressive relapse/recurrence, as well as (b) linear mixed effect models to predict self-rated depressive symptoms assessed with the Beck's depression inventory (BDI-II). $D A$ dysfunctional attitudes, $P A T$ positive automatic thoughts, NAT negative automatic thoughts. Solid lines indicate significant effects; dotted lines indicate non-significant effects. Levels of two-tailed significance are denoted with ${ }^{*} p<0.050$, ${ }^{* *} p<0.010,{ }^{* * *} p<0.001$. Values in brackets indicate coefficients of less complex models (cf. Table 4). Italic values indicate marginal explained variance $\left(\mathrm{R}_{\mathrm{m}}{ }^{2}\right.$, i.e., by fixed effects) and conditional explained variance $\left(\mathrm{R}_{\mathrm{c}}{ }^{2}\right.$, i.e., by fixed and random effects), respectively

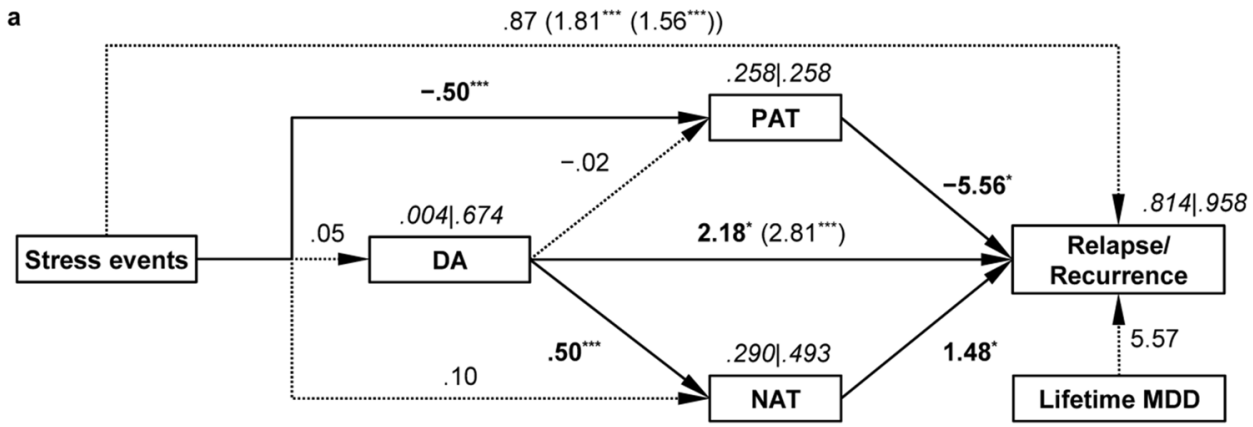

b

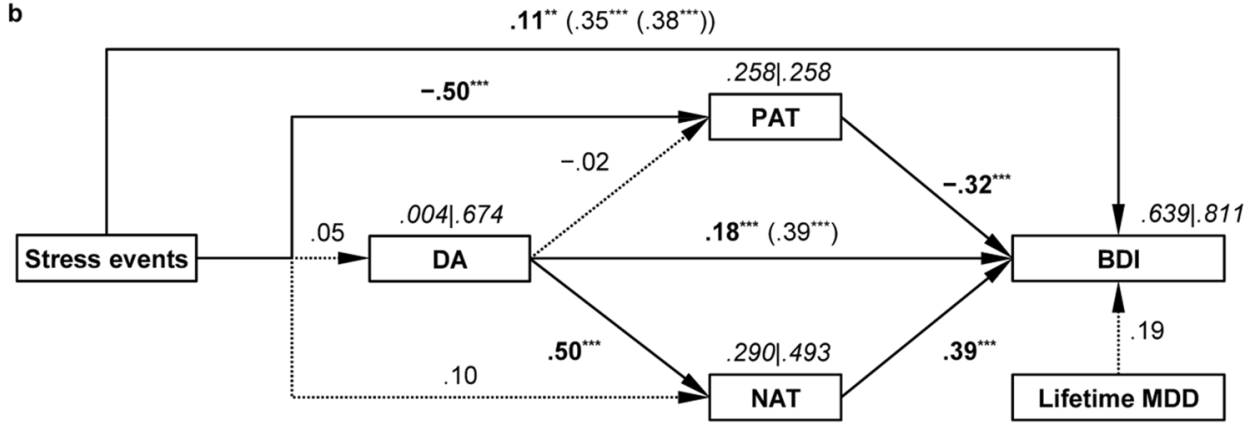

inpatient treatment. Furthermore, experiencing negative and positive stressful events implicated a strong reduction of PAT, specifically within the first four months after discharge. In comparison, DA remained relatively stable over the 16-month follow-up and did not vary with experiencing stressful events. More DA implicated the occurrence of more NAT but were not related to the occurrence of PAT. Overall, our results suggest that depressive relapse/recurrence is mediated through the stress-related decline of PAT along with a persistent presence of more DA and related NAT.

In par with previous longitudinal studies (Brouwer et al., 2019), remitted patients with more DA had a significantly higher risk for depressive relapse/recurrence. This finding corroborates the view of DA as a risk trait that remains temporarily inactive but latently present even in the state of remitted depression (Beck, 1979; Conway et al., 2015; Teasdale, 1988). Our mediation analyses suggest that DA unfold their detrimental role in depressive relapse/recurrence both directly and indirectly via an increased production of NAT. As previously shown (Riley et al., 2017; Tang et al., 2020), NAT were more closely correlated to depressive symptoms when compared to DA. These findings support the theoretical perspective that NAT (as a proximal risk variable) emerge as the situation-specific, cognitively salient expression of deep-seated DA (as a distal risk trait) (Hollon \& Kendall, 1980; Hollon et al., 1996; Wenzel, 2012).

In addition, it is postulated that latent DA can be reactivated upon exposure to stressful events (Beck \& Haigh, 2014; Scher et al., 2005). Therefore, based on previous evidence (Lewinsohn et al., 1999, 2001), we hypothesized that stressful event exposure reactivates latent DA in remitted patients which increases the occurrence of NAT. However, among our remitted depressed patients, DA and the occurrence of NAT did not increase upon encountering stressful events. Accordingly, DA and NAT did not mediate the negative effect of stressful events on depressive relapse/ recurrence, which has also been reported previously (Lethbridge \& Allen, 2008; Marchetti et al., 2021; Wojnarowski et al., 2019). Instead, patients experiencing depressive relapse/recurrence after discharge reported more DA and NAT during the follow-up phase. This suggests that their negative schemas and related cognitions remained activated despite achieving symptomatic remission in acute-phase inpatient treatment. Possibly, depressogenic schemas and cognitions in moderate to severely depressed patients do not need to be reactivated by environmental stressors but remain permanently activated as a cognitive vulnerability to depression which is independent of stress.

In fact, cognitive scar theories surmise that, with each depressive episode, environmental stressors become less important for depression recurrence. Subsequent episodes can also be evoked through permanently activated negative cognitions (Burcusa \& Iacono, 2007; Monroe et al., 2019). Consequently, successful relapse/recurrence prevention requires disrupting or at least deactivating patients' maladaptive thought patterns. However, there is a large body of literature suggesting that although cognitive therapy alters surface negative thinking in depression, deep-seated 
negative cognitive schemas are often unaffected by therapy (see Garratt et al., 2007; Ingram et al., 1998 for extensive discussions). Beside negative depressogenic schemas, all individuals possess adaptive, constructive schemas (Clark et al., 1999; Ingram et al., 1995; Otani et al., 2017). Therefore, effective relapse prevention in depression could be achieved if therapies can facilitate initiation, formation, and connection of existing positive self-concepts and cognitions. Regarding positive cognitions, in our study, the course of the patients' PAT was independent of their DA and NAT. However, encountering stressful events in the follow-up phase was associated with a strong reduction of PAT, specifically within the first four months after discharge. Importantly, the stress-associated reduction of PAT was not mediated by changes in DA. In line with previous studies (Ingram et al., 1995; Missel \& Sommer, 1983; Rojas et al., 2016), PAT were highly predictive of depressive relapse/recurrence. Our finding suggests that returning to the daily environment after an inpatient treatment and being confronted with daily hassles and challenges appears to exert its negative effect on depressive relapse/recurrence through rapid decrease of protective PAT that had been acquired during the treatment.

Thus, the ability to generate positive cognitions despite daily hassles and stressful conditions could be crucial for remission maintenance. It is indetermined why individuals differ in their ability to refocus on the positive, and whether there are functional attitudes or positive self-concepts expressed as PAT. As of now, influence of positive selfconcepts such as self-efficacy, locus of control, and sense of coherence on the occurrence of PAT and their fluctuation upon stress are not thoroughly researched (e.g., Otani et al., 2017). Future studies should explore these relationships to establish suitable starting points for sustainable maintenance therapy. Conceivably, positive cognitions may not be as easily activated in response to stress in remitted/recurrent depressed patients as in healthy or mildly depressed individuals (Clark et al., 1999; Rojas et al., 2016). Therefore, therapeutic techniques are needed to activate and strengthen constructive schemas and thoughts to facilitate their habitual activation even in the occasions of everyday stress and negative life events. Previous findings and our study results (Ingram et al., 1995; Missel \& Sommer, 1983; Rojas et al., 2016) emphasize that retaining positive cognitions appears crucial to reduce relapse/recurrence risk even in patients with a history of multiple depressive episodes.

In sum, we found relapse/recurrence in remitted depressed patients was essentially associated with two processes that temporarily overlap: (1), everyday stressors lead to a reduced PAT occurrence quickly after discharge from the inpatient setting, and parallel to this (2), time-stable DA favor the occurrence of NAT during the follow-up phase. This also suggests there might be a "critical ratio" of NAT to PAT, with a dominance of NAT over PAT posing a risk for relapse/recurrence. Future longitudinal studies are required to examine whether an imbalance of negative and positive cognitions is key to depressive relapse/recurrence.

However, previous longitudinal studies indicated that the temporal direction between automatic thoughts and the course of depression might be inconsistent (Riley et al., 2017). As Riley et al. (2017), we have evaluated the patients' automatic thoughts at a time interval of every four months. However, due to their state character, automatic thoughts are unlikely to be a predictor of depressive symptoms four months later. Future studies should assess stress, automatic thoughts, and depressive symptoms more frequently, preferably on a daily basis, for example, using mobile phone applications. Such "ecological momentary assessments" would allow testing the sequential nature of daily stress exposure, automatic thoughts, and mood changes.

\section{Implications for Therapeutic Practice}

Our results have relevant implications for therapeutic practice and suggest considering additional therapeutically relevant variables in the cognitive model of depression. First, the maintenance of depressive remission appears to be related to retaining PAT despite of exposure to stressful events after discharge. For patients, it is therefore relevant to derive a realistic perspective on their life circumstances and relevant coping resources. Development of positive or more realistic thoughts can be encouraged through various approaches such as self-induction techniques (Meichenbaum, 2009), positive-psychology interventions (Seligman, 2002, 2011), controlling thoughts techniques (Lewinsohn et al., 2010), as well as mindfulness methods (e.g., MBCT; Segal et al., 2002). Such techniques can help increasing the patients' awareness of the current situation and their needs, and imparting strategies, mechanisms, and actions to maintain an emotional and physical balance.

Second, sustainably maintaining remission would require effective strategies to consistently reduce DA and associated NAT. Inpatient acute-phase cognitive therapy is likely to be insufficient in altering deep-seated negative cognitive schemas. Autobiographical work, which is typically administered in subsequent outpatient settings, has been proven effective to help patients to elucidate the origins of their DA in their own history. It further enables patients to understand the "functionality" of their DA, and, thereby, increases their willingness to apply learned therapeutic strategies to overcome existing dysfunctional perspectives. Integrating methods from various theories is recommended such as techniques to recognize and change NAT (Beck et al., 1979) and cognitive restructuring to modify DA (e.g., Beck, 1979; Ellis \& Dryden, 2007)

Beside cognitive restructuring, patients may learn to detach from their dysfunctional cognitive patterns through 
"metacognitive" abilities. To this end, MBCT aims to enable patients to become aware of their internal (e.g., dysfunctional attitudes) and external experiences (e.g., stressful events), to accept them through detaching from their negatively biased cognitive patterns, and thereby, to cease worrying and ruminating about these experiences (Segal et al., 2002). In their review, Bockting et al. (2015) argue that MBCT could be specifically beneficial for patients with chronic and recurrent depression (for meta-analyses see Goldberg et al., 2019; Kuyken et al., 2016). Rumination as the uncontrollable and unwanted recurrence of thoughts about negative self-concepts and self-evaluations is associated with an increased risk of relapse/recurrence in depression (Nolen-Hoeksema et al., 2008; Rogers \& Joiner, 2017). Consequently, the use of cognitive therapy strategies focused on rumination such as the Response Style Theory by Watkins (2018) is recommended (Marchetti et al., 2021).

\section{Limitations and Future Directions}

Strengths of this study include its multiple follow-up measurements (five times within 16 months), enabling the meaningful analysis of the courses of exposure to stressful events, DA, NAT, PAT, and depression, as well as their interplay. Although the sample size was sufficiently powered to test longitudinal mediation effects (Pan et al., 2018), the study cohort was relatively small and has been recruited using convenience sampling, which is not representative for the patient population. Therefore, replication studies within larger cohorts are required to generalize our findings on patients who differ from the present sample (e.g., in the severity or chronicity of depression, comorbidities, sociocultural influences). Our analysis model is based on the theoretical assumptions of Beck's theory (1967) and was expanded to include PAT. As an alternative to our meditation perspective, it is conceivable that DA and automatic thoughts moderate the influence of stress on depressive relapse/recurrence (Marchetti et al., 2021). Future studies with larger cohorts could examine moderated mediation effects, and may also consider other cognitive vulnerability variables assumed by Beck (e.g., cognitive distortions, cognitive triad) along with other risk factors (e.g., rumination, maladaptive coping styles) and resilience factors such as positive self-concepts (e.g., functional attitudes, self-efficacy, locus of control, sense of coherence). Moreover, it is commonly surmised that negative cognitive schemas are formed by negative life events, which warrants the investigation of etiological risk factors such as childhood maltreatment and major life events in the prospect of depression relapse/recurrence. Finally, regarding therapeutic methods, it is highly relevant to investigate which therapeutic techniques in outpatient follow-up care (psychotherapy, psychiatry, and counseling) benefit remission maintenance, and whether antidepressant and other psychotropic medication influences cognitive risk variables and benefits the stability of therapy success.

\section{Conclusions}

Following discharge from inpatient treatment, relapse/recurrence risk in remitted depressive patients is strongly associated with rapidly declining PAT due to everyday stressors as well as the presence of more DA and related NAT. Possibly, it is the imbalance of persistent NAT and decreasing PAT which leads to depressive relapse/recurrence. Research is needed to improve therapeutic techniques to (1) strengthen positive self-concepts and retain PAT when coping with stress, and (2) reduce DA and NAT effectively and sustainably. Moreover, optimizing the coordinated interaction of inpatient and subsequent outpatient care is warranted to benefit the maintenance of depression remission. Preventing depressive relapse/recurrence remains the major challenge in improving the patients' quality of life and in reducing the socio-economic costs of chronic and recurrent depression.

Supplementary Information The online version contains supplementary material available at https://doi.org/10.1007/s10608-021-10280-y.

Acknowledgements We thank the Schön Clinic Roseneck for their support in data collection. We thank Suchithra Varadarajan for proof reading.

Author Contributions RR developed the study concept and conducted the study setup and data collection. AB performed the statistical data analysis. RR and $\mathrm{AB}$ drafted the paper under supervision of $\mathrm{MH}$. All authors contributed to the interpretation of data, critically revised the manuscript, and approved the final manuscript.

Funding Open Access funding enabled and organized by Projekt DEAL.

Data Availability The dataset for this manuscript is not publicly available and may not be passed on to third parties outside the research project. We do not have the consent of the ethics committee or our participants to grant access to or insight in the collected data. The dataset contains sensitive personal and clinical information that might allow identifying individual participants.

\section{Declarations}

Conflict of Interest Roberto Rojas, Alexander Behnke, and Martin Hautzinger declare that they have no conflict of interest.

Ethical Approval The study was conducted in accordance with the Declaration of Helsinki and the APA ethical standards, and all procedures were approved by the University of Tübingen Institutional Review Board at 01.02.2009.

Informed Consent Informed consent was obtained from all individual participants included in the study. 
Research Involving Human and Animal Participants No animal studies were carried out by the authors for this article.

Open Access This article is licensed under a Creative Commons Attribution 4.0 International License, which permits use, sharing, adaptation, distribution and reproduction in any medium or format, as long as you give appropriate credit to the original author(s) and the source, provide a link to the Creative Commons licence, and indicate if changes were made. The images or other third party material in this article are included in the article's Creative Commons licence, unless indicated otherwise in a credit line to the material. If material is not included in the article's Creative Commons licence and your intended use is not permitted by statutory regulation or exceeds the permitted use, you will need to obtain permission directly from the copyright holder. To view a copy of this licence, visit http://creativecommons.org/licenses/by/4.0/.

\section{References}

Alloy, L. B., Clements, C., \& Kolden, G. (1985). The cognitive diathesis-stress theories of depression: Therapeutic implications. In S. Reiss \& R. R. Bootzin (Eds.), Theoretical issues in behavior therapy (pp. 379-410). Academic Press.

Ayano, G., Solomon, M., \& Abraha, M. (2018). A systematic review and meta-analysis of epidemiology of depression in people living with HIV in East Africa. BMC Psychiatry. https://doi.org/10. 1186/s12888-018-1835-3

Bakdash, J. Z., \& Marusich, L. R. (2016). rmcorr: Repeated measures correlation (Version 0.1.0) [R package]. Retrieved from https:// cran.r-project.org/web/packages/rmcorr/rmcorr.pdf

Baron, R. M., \& Kenny, D. A. (1986). The moderator-mediator variable distinction in social psychological research: Conceptual, strategic, and statistical considerations. Journal of Personality and Social Psychology, 51(6), 1173-1182. https://doi.org/10.1037/ 0022-3514.51.6.1173

Bates, D., Mächler, M., Bolker, B., \& Walker, S. (2015). Fitting linear mixed-effects models using Ime4. Journal of Statistical Software, 67(1), 1-48. https://doi.org/10.18637/jss.v067.i01

Beck, A. T. (1967). Depression: Clinical, experimental, and theoretical aspects. Hoeber Medical Division, Harper \& Row.

Beck, A. T. (1979). Cognitive therapy and the emotional disorders. Penguin.

Beck, A. T. (2008). The evolution of the cognitive model of depression and its neurobiological correlates. American Journal of Psychiatry, 165(8), 969-977. https://doi.org/10.1176/appi.ajp.2008. 08050721

Beck, A. T., \& Haigh, E. A. P. (2014). Advances in cognitive theory and therapy: The generic cognitive model. Annual Review of Clinical Psychology, 10(1), 1-24. https://doi.org/10.1146/annur ev-clinpsy-032813-153734

Beck, A. T., Rush, J., Shaw, B. F., \& Emery, G. W. (1979). Cognitive therapy of depression. Guilford press.

Beshai, S., Dobson, K. S., Bockting, C. L. H., \& Quigley, L. (2011). Relapse and recurrence prevention in depression: Current research and future prospects. Clinical Psychology Review, 31(8), 13491360. https://doi.org/10.1016/j.cpr.2011.09.003

Bockting, C. L., Hollon, S. D., Jarrett, R. B., Kuyken, W., \& Dobson, K. (2015). A lifetime approach to major depressive disorder: The contributions of psychological interventions in preventing relapse and recurrence. Clinical Psychology Review, 41, 16-26. https:// doi.org/10.1016/j.cpr.2015.02.003

Brouwer, M. E., Williams, A. D., Forand, N. R., DeRubeis, R. J., \& Bockting, C. L. H. (2019). Dysfunctional attitudes or extreme response style as predictors of depressive relapse and recurrence after mobile cognitive therapy for recurrent depression. Journal of Affective Disorders, 243, 48-54. https://doi.org/10.1016/j.jad. 2018.09.002

Burcusa, S. L., \& Iacono, W. G. (2007). Risk for recurrence in depression. Clinical Psychology Review, 27(8), 959-985. https://doi.org/ 10.1016/j.cpr.2007.02.005

Cambridge, O. R., Knight, M. J., Mills, N., \& Baune, B. T. (2018). The clinical relationship between cognitive impairment and psychosocial functioning in major depressive disorder: A systematic review. Psychiatry Research, 269, 157-171. https://doi.org/10. 1016/j.psychres.2018.08.033

Chahar Mahali, S., Beshai, S., Feeney, J. R., \& Mishra, S. (2020). Associations of negative cognitions, emotional regulation, and depression symptoms across four continents: International support for the cognitive model of depression. BMC Psychiatry. https:// doi.org/10.1186/s12888-019-2423-x

Chen, Y., Bennett, D., Clarke, R., Guo, Y., Yu, C., Bian, Z., Ma, L., Huang, Y., Sun, Q., Zhang, N., Zheng, X., Chen, J., Peto, R., Kendler, K. S., Li, L., \& Chen, Z. (2017). Patterns and correlates of major depression in Chinese adults: A cross-sectional study of 0.5 million men and women. Psychological Medicine, 47(5), 958-970. https://doi.org/10.1017/S0033291716002889

Clark, D. A., Beck, A. T., \& Alford, B. A. (1999). Scientific foundations of cognitive theory and therapy of depression. John Wiley.

Conway, C. C., Slavich, G. M., \& Hammen, C. (2015). Dysfunctional attitudes and affective responses to daily stressors: Separating cognitive, genetic, and clinical influences on stress reactivity. Cognitive Therapy and Research, 39(3), 366-377. https://doi.org/10. 1007/s10608-014-9657-1

Cuijpers, P., Karyotaki, E., Weitz, E., Andersson, G., Hollon, S. D., \& van Straten, A. (2014). The effects of psychotherapies for major depression in adults on remission, recovery and improvement: A meta-analysis. Journal of Affective Disorders, 159, 118-126. https://doi.org/10.1016/j.jad.2014.02.026

Dobson, K. S., \& Shaw, B. F. (1986). Cognitive assessment with major depressive disorders. Cognitive Therapy and Research, 10(1), 13-29. https://doi.org/10.1007/BF01173379

Dozois, D. J. A. (2007). Stability of negative self-structures: A longitudinal comparison of depressed, remitted, and nonpsychiatric controls. Journal of Clinical Psychology, 63(4), 319-338. https:// doi.org/10.1002/jclp.20349

Dozois, D. J. A., Bieling, P. J., Patelis-Siotis, I., Hoar, L., Chudzik, S., McCabe, K., \& Westra, H. A. (2009). Changes in self-schema structure in cognitive therapy for major depressive disorder: A randomized clinical trial. Journal of Consulting and Clinical Psychology, 77(6), 1078-1088. https://doi.org/10.1037/a0016886

Ellis, A., \& Dryden, W. (2007). The practice of rational emotive behavior therapy. Springer.

Ertekin, H., Beyazit, F., \& Sahin, B. (2018). Evaluation of psychiatric symptoms and automatic negative thoughts among menopausal women. Medicine Science. https://doi.org/10.5455/medscience. 2018.07.8771

Faissner, M., Kriston, L., Moritz, S., \& Jelinek, L. (2018). Course and stability of cognitive and metacognitive beliefs in depression. Depression and Anxiety, 35(12), 1239-1246. https://doi.org/10. 1002/da.22834

Furlong, M., \& Oei, T. P. S. (2002). Changes to automatic thoughts and dysfunctional attitudes in-group CBT for depression. Behavioural and Cognitive Psychotherapy, 30(3), 351-360. https://doi.org/10. 1017/S1352465802003107

Gao, J.-L., Wang, L.-H., Yin, X.-Q., Hsieh, H.-F., Rost, D. H., Zimmerman, M. A., \& Wang, J.-L. (2019). The promotive effects of peer support and active coping in relation to negative life events and depression in Chinese adolescents at boarding schools. Current Psychology. https://doi.org/10.1007/s12144-019-0143-5 
Garratt, G., Ingram, R. E., Rand, K. L., \& Sawalani, G. (2007). Cognitive processes in cognitive therapy: Evaluation of the mechanisms of change in the treatment of depression. Clinical Psychology, 14(3), 224-239. https://doi.org/10.1111/j.1468-2850.2007. 00081.x

Goldberg, S. B., Tucker, R. P., Greene, P. A., Davidson, R. J., Kearney, D. J., \& Simpson, T. L. (2019). Mindfulness-based cognitive therapy for the treatment of current depressive symptoms: A metaanalysis. Cognitive Behaviour Therapy, 48(6), 445-462. https:// doi.org/10.1080/16506073.2018.1556330

Härter, M., Schorr, S., \& Schneider, F. (Eds.). (2017). S3-Leitlinie/ Nationale Versorgungsleitlinie Unipolare Depression: Interdisziplinäre S3-Praxisleitlinien (2. Auflage, AWMF-Register-Nr.: $N v l$-005). Springer.

Hautzinger, M., Joormann, J., \& Keller, F. (2005). Die Skala Dysfunktionaler Einstellungen (DAS). Hogrefe.

Hautzinger, M., Keller, F., \& Kühner, C. (2006). Beck DepressionsInventar II (BDI II), Testhandbuch. Frankfurt a. M. Harcourt Test Services.

Hetolang, L. T., \& Amone-P'Olak, K. (2018). The associations between stressful life events and depression among students in a university in Botswana. South African Journal of Psychology, 48(2), 255-267. https://doi.org/10.1177/0081246317711793

Hjemdal, O., Stiles, T., \& Wells, A. (2013). Automatic thoughts and meta-cognition as predictors of depressive or anxious symptoms: A prospective study of two trajectories. Scandinavian Journal of Psychology, 54(2), 59-65. https://doi.org/10.1111/sjop.12010

Hollon, S. D., DeRubeis, R. J., \& Evans, M. D. (1996). Cognitive therapy in the treatment and prevention of depression. In P. M. Salkovskis (Ed.), Frontiers of cognitive therapy (pp. 293-317). The Guilford Press.

Hollon, S. D., \& Kendall, P. C. (1980). Cognitive self-statements in depression: Development of an automatic thoughts questionnaire. Cognitive Therapy and Research, 4(4), 383-395. https://doi.org/ 10.1007/BF01178214

Huffziger, S., Meyer, T. D., Seemann, S., Horn, A. B., Groen, G., \& Pössel, P. (2008). Evaluation Erfassung positiver und negativer automatischer Gedanken bei Kindern und Jugendlichen. Zeitschrift für Klinische Psychologie und Psychotherapie, 37(4), 255-262. https://doi.org/10.1026/1616-3443.37.4.255

Ingram, R. E., Kendall, P. C., Siegle, G., Guarino, J., \& McLaughlin, S. C. (1995). Psychometric properties of the positive automatic thoughts questionnaire. Psychological Assessment, 7(4), 495-507. https://doi.org/10.1037/1040-3590.7.4.495

Ingram, R. E., Miranda, J., \& Segal, Z. V. (1998). Cognitive vulnerability to depression. Guilford Press.

Jacobs, R. H., Reinecke, M. A., Gollan, J. K., \& Kane, P. (2008). Empirical evidence of cognitive vulnerability for depression among children and adolescents: A cognitive science and developmental perspective. Clinical Psychology Review, 28(5), 759-782. https://doi.org/10.1016/j.cpr.2007.10.006

Jeanne, M., Gross, J. J., Persons, J. B., \& Hahn, J. (1998). Mood matters: Negative mood induction activates dysfunctional attitudes in women vulnerable to depression. Cognitive Therapy and Research, 22(4), 363-376. https://doi.org/10.1023/A:1018709212 986

Johnston, K. M., Powell, L. C., Anderson, I. M., Szabo, S., \& Cline, S. (2019). The burden of treatment-resistant depression: A systematic review of the economic and quality of life literature. Journal of Affective Disorders, 242, 195-210. https://doi.org/10.1016/j. jad.2018.06.045

Kendler, K. S., Thornton, L. M., \& Gardner, C. O. (2000). Stressful life events and previous episodes in the etiology of major depression in women: An evaluation of the "kindling" hypothesis. American Journal of Psychiatry, 157(8), 1243-1251. https://doi.org/10. 1176/appi.ajp.157.8.1243
Kuyken, W., Warren, F. C., Taylor, R. S., Whalley, B., Crane, C., Bondolfi, G., Hayes, R., Huijbers, M., Ma, H., Schweizer, S., Segal, Z., Speckens, A., Teasdale, J. D., Heeringen, K. V., Williams, M., Byford, S., Byng, R., \& Dalgleish, T. (2016). Efficacy of mindfulness-based cognitive therapy in prevention of depressive relapse: An individual patient data meta-analysis from randomized trials. JAMA Psychiatry, 73(6), 565. https://doi.org/10.1001/jamapsychi atry.2016.0076

Kuznetsova, A., Brockhoff, P. B., \& Christensen, R. H. B. (2016). lmerTest: Tests in linear mixed effects models (Version 2.0-32) [R package]. Retrieved from https://CRAN.R-project.org/packa ge $=$ lmerTest

Kwon, S.-M., \& Oei, T. P. S. (1994). The roles of two levels of cognitions in the development, maintenance, and treatment of depression. Clinical Psychology Review, 14(5), 331-358. https://doi.org/ 10.1016/0272-7358(94)90032-9

Lakdawalla, Z., Hankin, B. L., \& Mermelstein, R. (2007). Cognitive theories of depression in children and adolescents: A conceptual and quantitative review. Clinical Child and Family Psychology Review, 10(1), 1-24. https://doi.org/10.1007/s10567-006-0013-1

Lethbridge, R., \& Allen, N. B. (2008). Mood induced cognitive and emotional reactivity, life stress, and the prediction of depressive relapse. Behaviour Research and Therapy, 46(10), 1142-1150. https://doi.org/10.1016/j.brat.2008.06.011

Lewinsohn, P. M., Allen, N. B., Seeley, J. R., \& Gotlib, I. H. (1999). First onset versus recurrence of depression: Differential processes of psychosocial risk. Journal of Abnormal Psychology, 108(3), 483-489. https://doi.org/10.1037/0021-843X.108.3.483

Lewinsohn, P. M., Joiner, T. E., \& Rohde, P. (2001). Evaluation of cognitive diathesis-stress models in predicting major depressive disorder in adolescents. Journal of Abnormal Psychology, 110(2), 203-215. https://doi.org/10.1037/0021-843X.110.2.203

Lewinsohn, P. M., Muñoz, R. F., Youngren, M. A., \& Zeiss, A. M. (2010). Control your depression: Revised and updated. Simon \& Schuster.

Lewinsohn, P. M., Rohde, P., \& Gau, J. M. (2003). Comparability of self-report checklist and interview data in the assessment of stressful life events in young adults. Psychological Reports, 93(2), 459-471. https://doi.org/10.2466/pr0.2003.93.2.459

Marchetti, I., Pössel, P., \& Koster, E. H. W. (2021). The architecture of cognitive vulnerability to depressive symptoms in adolescence: A longitudinal network analysis study. Research on Child and Adolescent Psychopathology, 49(2), 267-281. https://doi.org/10. 1007/s10802-020-00733-5

Meichenbaum, D. (2009). Stress inoculation training. In W. T. O'Donohue \& J. E. Fisher (Eds.), General principles and empirically supported techniques of cognitive behavior therapy (pp. 627-630). Wiley.

Miloseva, L., Vukosavljevic-Gvozden, T., Milosev, V., \& Davis, T. (2018). Can we predict and prevent subclinical depression in adolescents? The Journal of Nervous and Mental Disease, 206(2), 102-107. https://doi.org/10.1097/NMD.0000000000000783

Missel, P., \& Sommer, G. (1983). Depression and self-verbalization. Cognitive Therapy and Research, 7(2), 141-148. https://doi.org/ 10.1007/BF01190067

Mohammadkhani, P., Bagheri, M., Dobson, K. S., Eskandari, E., Dejman, M., Bass, J., \& Abdi, F. (2020). Negative thoughts in depression: A study in Iran. International Journal of Psychology, 55(1), 83-89. https://doi.org/10.1002/ijop.12541

Monroe, S. M., Anderson, S. F., \& Harkness, K. L. (2019). Life stress and major depression: The mysteries of recurrences. Psychological Review, 126(6), 791. https://doi.org/10.1037/rev0000157

Nolen-Hoeksema, S., Wisco, B. E., \& Lyubomirsky, S. (2008). Rethinking rumination. Perspectives on Psychological Science, 3(5), 400-424. https://doi.org/10.1111/j.1745-6924.2008.00088.x 
Oei, T. P. S., \& Sullivan, L. M. (1999). Cognitive changes following recovery from depression in a group cognitive-behaviour therapy program. Australian \& New Zealand Journal of Psychiatry, 33(3), 407-415. https://doi.org/10.1046/j.1440-1614.1999.00562.x

Otani, K., Suzuki, A., Matsumoto, Y., \& Shirata, T. (2017). Relationship of negative and positive core beliefs about the self with dysfunctional attitudes in three aspects of life. Neuropsychiatric Disease and Treatment, 13, 2585-2588. https://doi.org/10.2147/ NDT.S150537

Otto, M. W., Teachman, B. A., Cohen, L. S., Soares, C. N., Vitonis, A. F., \& Harlow, B. L. (2007). Dysfunctional attitudes and episodes of major depression: Predictive validity and temporal stability in never-depressed, depressed, and recovered women. Journal of Abnormal Psychology, 116(3), 475-483. https://doi.org/10.1037/ 0021-843X.116.3.475

Pan, H., Liu, S., Miao, D., \& Yuan, Y. (2018). Sample size determination for mediation analysis of longitudinal data. BMC Medical Research Methodology, 18(1), 32. https://doi.org/10.1186/ s12874-018-0473-2

Pössel, P., \& Knopf, K. (2008). An experimental test of the maintenance and vulnerability hypothesis of depression in consideration of the cognitive hierarchy. Depression and Anxiety, 25(9), E47E55. https://doi.org/10.1002/da.20313

Pössel, P., Seemann, S., \& Hautzinger, M. (2005). Evaluation eines deutschsprachigen Instrumentes zur Erfassung positiver und negativer automatischer Gedanken. Zeitschrift für Klinische Psychologie und Psychotherapie, 34(1), 27-34. https://doi.org/10. 1026/1616-3443.34.1.27

Riley, K. E., Lee, J. S., \& Safren, S. A. (2017). The relationship between automatic thoughts and depression in a cognitive-behavioral treatment for people living with HIV/AIDS: Exploring temporality and causality. Cognitive Therapy and Research, 41(5), 712-719. https://doi.org/10.1007/s10608-017-9839-8

Rogers, M. L., \& Joiner, T. E. (2017). Rumination, suicidal ideation, and suicide attempts: A meta-analytic review. Review of General Psychology, 21(2), 132-142. https://doi.org/10.1037/gpr0000101

Rojas, R., Geissner, E., \& Hautzinger, M. (2014). Kognitive Reaktivität und Stressbelastung als Prädiktoren eines Rezidivs bei remittiert depressiven Personen. Zeitschrift für Klinische Psychologie und Psychotherapie, 43(1), 17-26. https://doi.org/10.1026/1616-3443/ a000251

Rojas, R., Geissner, E., \& Hautzinger, M. (2015). DAS-18 Form A und B: Entwicklung und psychometrische Überprüfung von zwei vergleichbaren Kurzversionen der Skala Dysfunktionaler Einstellungen (DAS). Diagnostica, 61(4), 173-183. https://doi.org/10. 1026/0012-1924/a000123

Rojas, R., Ilg, T., Geissner, E., \& Hautzinger, M. (2016). Auswirkungen von automatischen Gedanken und psychologischer Flexibilität aus die depressive Symptomatik und Rückfallwahrscheinlichkeit. Verhaltenstherapie, 26(4), 270-277. https://doi.org/10.1159/ 000452920

Rush, A. J., Trivedi, M. H., Ibrahim, H. M., Carmody, T. J., Arnow, B., Klein, D. N., Markowitz, J. C., Ninan, P. T., Kornstein, S., Manber, R., Thase, M. E., Kocsis, J. H., \& Keller, M. B. (2003). The 16-Item quick inventory of depressive symptomatology (QIDS), clinician rating (QIDS-C), and self-report (QIDS-SR): A psychometric evaluation in patients with chronic major depression. Biological Psychiatry, 54(5), 573-583. https://doi.org/10.1016/ S0006-3223(02)01866-8

Scher, C. D., Ingram, R. E., \& Segal, Z. V. (2005). Cognitive reactivity and vulnerability: Empirical evaluation of construct activation and cognitive diatheses in unipolar depression. Clinical Psychology Review, 25(4), 487-510. https://doi.org/10.1016/j.cpr.2005.01.005

Segal, Z. V., Gemar, M., \& Williams, S. (1999). Differential cognitive response to a mood challenge following successful cognitive therapy or pharmacotherapy for unipolar depression. Journal of
Abnormal Psychology, 108(1), 3-10. https://doi.org/10.1037/ 0021-843X.108.1.3

Segal, Z. V., Kennedy, S., Gemar, M., Hood, K., Pedersen, R., \& Buis, T. (2006). Cognitive reactivity to sad mood provocation and the prediction of depressive relapse. Archives of General Psychiatry, 63(7), 749. https://doi.org/10.1001/archpsyc.63.7.749

Segal, Z. V., Williams, J. M. G., \& Teasdale, J. D. (2002). Mindfulnessbased cognitive therapy for depression: A new approach to preventing relapse. Guilford Press.

Seligman, M. E. P. (2002). Authentic happiness. Simon \& Schuster.

Seligman, M. E. P. (2011). Flourish: A visionary new understanding of happiness and well-being. Free Press.

Shiraishi, S. (2005). Cognitive therapy for reducing and preventing depressive moods. The Japanese Journal of Educational Psychology, 53(2), 252-262. https://doi.org/10.5926/jjep1953.53.2_252

Smith, E. M., Reynolds, S., Orchard, F., Whalley, H. C., \& Chan, S. W. (2018). Cognitive biases predict symptoms of depression, anxiety and wellbeing above and beyond neuroticism in adolescence. Journal of Affective Disorders, 241, 446-453. https://doi.org/10. 1016/j.jad.2018.08.051

Tang, X., Tang, S., Ren, Z., \& Wong, D. F. K. (2020). Psychological risk and protective factors associated with depressive symptoms among adolescents in secondary schools in China: A systematic review and meta-analysis. Children and Youth Services Review, 108, 104680. https://doi.org/10.1016/j.childyouth.2019.104680

Teasdale, J. D. (1988). Cognitive vulnerability to persistent depression. Cognition \& Emotion, 2(3), 247-274. https://doi.org/10. 1080/02699938808410927

Thomsen, D. K. (2006). The association between rumination and negative affect: A review. Cognition \& Emotion, 20(8), 1216-1235. https://doi.org/10.1080/02699930500473533

Tingley, D., Yamamoto, T., Hirose, K., Keele, L., \& Imai, K. (2014). Mediation: $R$ package for causal mediation analysis. Journal of Statistical Software, 59(5), 1-40. https://doi.org/10.18637/jss. v059.i05

Trivedi, M. H., Rush, A. J., Ibrahim, H. M., Carmody, T. J., Biggs, M. M., Suppes, T., Crismon, M. L., Shores-Wilson, K., Toprac, M. G., Dennehy, E. B., Witte, B., \& Kashner, T. M. (2004). The inventory of depressive symptomatology, clinician rating (IDSC) and self-report (IDS-SR), and the quick inventory of depressive symptomatology, clinician rating (QIDS-C) and self-report (QIDS-SR) in public sector patients with mood disorders: A psychometric evaluation. Psychological Medicine, 34(1), 73-82. https://doi.org/10.1017/S0033291703001107

Vernon, P. A. (1993). Der Zahlen-Verbindungs-test and other trail-making correlates of general intelligence. Personality and Individual Differences, 14(1), 35-40. https://doi.org/10.1016/0191-8869(93) 90172-Y

Vittengl, J. R., Clark, L. A., Dunn, T. W., \& Jarrett, R. B. (2007). Reducing relapse and recurrence in unipolar depression: A comparative meta-analysis of cognitive-behavioral therapy's effects. Journal of Consulting and Clinical Psychology, 75(3), 475-488. https://doi.org/10.1037/0022-006X.75.3.475

Watkins, E. R. (2018). Rumination-focused cognitive-behavioral therapy for depression. Guilford Publications.

Wenzel, A. (2012). Modification of core beliefs in cognitive therapy. In I. R. De Oliveira (Ed.), Standard and innovative strategies in cognitive behavior therapy. InTech.

WHO. (2017). Depression and other common mental disorders: Global health estimates. World Health Organization.

Winkeljohn Black, S., \& Pössel, P. (2015). Integrating Beck's cognitive model and the response style theory in an adolescent sample. Journal of Youth and Adolescence, 44(1), 195-210. https://doi. org/10.1007/s10964-013-0087-2

Wittchen, H.-U., Jacobi, F., Klose, M., \& Ryl, L. (2010). Depressive Erkrankungen (No. Heft 51) (p. 46). Robert Koch-Institut. 
Wittchen, H.-U., Zaudig, M., \& Fydrich, T. (1997). Strukturiertes klinisches Interview für DSM-IV: SKID Achse I und II: Handanweisung. Hogrefe.

Wojnarowski, C., Firth, N., Finegan, M., \& Delgadillo, J. (2019). Predictors of depression relapse and recurrence after cognitive behavioural therapy: A systematic review and meta-analysis. Behavioural and Cognitive Psychotherapy, 47(5), 514-529. https://doi. org/10.1017/S1352465819000080

Yesilyaprak, N., Batmaz, S., Yildiz, M., Songur, E., \& Akpinar Aslan, E. (2019). Automatic thoughts, cognitive distortions, dysfunctional attitudes, core beliefs, and ruminative response styles in unipolar major depressive disorder and bipolar disorder: A comparative study. Psychiatry and Clinical Psychopharmacology, 29(4), 854-863. https://doi.org/10.1080/24750573.2019.1690815

Yu, T., Frei, A., ter Riet, G., \& Puhan, M. A. (2018). Impact of stressful life events on patients with chronic obstructive pulmonary disease. Respiration, 95(2), 73-79. https://doi.org/10.1159/000481714

Publisher's Note Springer Nature remains neutral with regard to jurisdictional claims in published maps and institutional affiliations. 